\title{
An Update on Effects of Creatine Supplementation on Performance: A Review
}

\author{
Harry F Dorrell*, Thomas I Gee and Geoff Middleton
}

School of Sport and Exercise Science, College of Social Sciences, University of Lincoln, Lincoln, England, UK

*Corresponding author: Harry F Dorrell, School of Sport and Exercise Science, College of Social Sciences, University of Lincoln, Lincoln, England, UK, Tel: +44(0)1522 887308; Fax: +44(0)1522 886026; E-mail: hdorrell@lincoln.ac.uk

Received date: February 18, 2016; Accepted date: March 10, 2016; Published date: March 17, 2016

Copyright: @ 2016 Dorrell HF, et al. This is an open-access article distributed under the terms of the Creative Commons Attribution License, which permits unrestricted use, distribution, and reproduction in any medium, provided the original author and source are credited.

\begin{abstract}
Supplementary creatine, available in many different forms but most commonly monohydrate, is a legal and reportedly safe to consume nutritional ergogenic aid. After searching internationally recognised research databases, this review provides and update on the current literature on the physiological effects of creatine supplementation on performance whilst also discussing the underlying physiology regarding the synthesis and dietary provision of creatine as well as addressing issues of safety and the ethical considerations of usage. Research has shown that regular consumption of supplementary creatine can raise associated content within skeletal muscle. Subsequently, there is an extensive, and still growing, body of the literature supporting the efficacy of creatine supplementation on enhancing exercise performance, exercise tolerance, muscle strength and lean body mass. Moreover, little scientific evidence exists showing any unfavourable effects on individuals who are free from illness and disease. This review consolidates the current literature and provides application to the athletic setting which is purposeful for those choosing to either recommend or consume this nutritional ergogenic aid. At this current time, a traditional loading and maintenance supplementation protocol is advised as contemporary research studies are still to unravel the benefits of alternative approaches.
\end{abstract}

Keywords: Creatine monohydrate; Exercise performance; Narrative review

\section{Abbreviations}

ATP: Adenosine Triphosphate; ADP: Adenosine Diphosphate; CR: Creatine; CK: Creatine-kinase; CRM: Creatine Monohydrate; PCr: Phosphocreatine

\section{Introduction}

Creatine (CR), a substance produced naturally within the human body, was initially discovered by the French scientist Chevreul in 1835 , and named after the Greek word 'kreas', meaning flesh [1]. By the early twentieth century CR could be pharmaceutically produced and the first nutritional CR supplementation studies were trialed [2,3]. However, it wasn't until the early 1990's that CR came into the public view following the 1992 Barcelona Olympics. Following these games several British Olympic athletes admitted to using CR after winning gold medals in their events [4]. By 1993, the first commercially available CR supplements were on the general market, classified as nutritional ergogenic aids [5]. CR is considered to be one of the most comprehensively studied and 'relatively' safe [6] ergogenic aids available to athletes.

Many varieties of CR have been formulated with the intention of increasing the proposed benefits (such as creatine citrate, creatine ethyl-ester, creatine gluconate). To date, creatine monohydrate (CRM) is the most widely used and scientifically researched form available, with over 2.5 million kilograms produced each year for oral supplementation alone [7,8]. There have been numerous studies focusing on highlighting the beneficial effects of supplementing with
$\mathrm{CR}$, with many recording significant performance effects. Reported performance enhancing properties of this supplement include, increased maximal work output [9], increased maximal strength [10], increased fat-free mass [11], decreased blood lactate accumulation [12] as well as promoting faster regeneration of adenosine triphosphate (ATP) during high intensity interval exercise [13]. Numerous studies illustrate that CR supplementation actively increases neuromuscular performance during short duration, anaerobic, intermittent exercises and is very beneficial to high power requiring athletes [13-16]. Interestingly, CR supplementation has shown to negatively affect range of motion [17] and does not influence field-based studies testing aerobic capacity [18].

\section{Creatine synthesis}

The guanidine compound of CR, or $\alpha$-methyl-guanidinoacetic acid, is a naturally occurring, nitrogenous amino acid composition, synthesised from three amino acids: glycine, arginine and methionine, and three enzymes: L-arginine:glycine amidinotransferase (AGAT), methionine adenosyltransferase (MAT) and guanidinoacetate methyltransferase (GAMT) $[1,13,19,20]$. The endogenous production of $\mathrm{CR}$ is initiated in the kidney by the transfer of arginine to glycine, (catalysed by AGAT), yielding L-ornithine and guanidinoacetate. This guanidinoacetate is then transported to the liver (hepatocyte cells) by the blood and methylated by S-adenosyl-L-methionine. This reaction produces free-form CR and S-adenosyl-L-homocysteine [1,19,21]. Storage occurs predominantly in the skeletal muscle (approximately 95\%) with the remaining 5\% distributed between the heart, brain, liver, kidneys and testes [22]. The muscle fibres are unable to synthesize CR and it must be absorbed and transferred via the blood, through the use of a specific protein; CR transporter protein, which enables distribution of CR throughout cells. 
Page 2 of 6

\section{Dietary Creatine}

A demand for CR is met by both, intestinal absorption from the diet (1-2 $\mathrm{g} / \mathrm{d})$, and endogenous production (1-2 g/d), with research showing that the latter is regulated by the former, and thus reduces if CR consumption is increased through supplementation or other dietary interventions [21]. The average CR pool (male: $70 \mathrm{~kg}$ ) is approximately 120-140 g, although this varies depending on fat-free mass [23] and skeletal muscle fibre type [22]. In general, oral supplementation aims to enhance this CR pool, with research showing a maximum increase of approximately $20 \%$ following a high dosage loading programme [13]. Although it is possible to consume CR rich foods (Table 1) and increase dietary intake naturally, it would potentially be counterproductive to athletic performance due to a subsequent rise in protein and lipid consumption. Furthermore, it has become apparent that with nearly all sources of CR coming from animal products, it is very difficult for the vegetarian/vegan athlete to increase intake outside of supplementation [24,25].

Research has shown that excess supplementation with CR $(>30 \mathrm{~g} / \mathrm{d})$ will generally result in cell saturation, after which surplus CR will be removed from the body by renal filtration. While some claim this can lead to an increased load on both the liver and kidneys, empirical research is yet to find any such side effects in healthy individuals $[26,27]$. It is also worth noting that once supplementation has ceased, serum CR levels will return to their pre-supplementation level within a 30-day period [22].

\begin{tabular}{|l|l|l|}
\hline Food source & Serving & Creatine content $(\mathbf{g})$ \\
\hline Herring & $225 \mathrm{~g} / 8 \mathrm{oz}$ & $2.0-4.0$ \\
\hline Pork & $225 \mathrm{~g} / 8 \mathrm{oz}$ & $1.5-2.5$ \\
\hline Salmon & $225 \mathrm{~g} / 8 \mathrm{oz}$ & $1.5-2.5$ \\
\hline Beef (lean) & $225 \mathrm{~g} / 8 \mathrm{oz}$ & $1.5-2.5$ \\
\hline Milk (1\% Fat) & $250 \mathrm{ml} / 8 \mathrm{oz}$ & 0.05 \\
\hline
\end{tabular}

Table 1: Creatine content as present in raw food products [28].

Research has shown that excess supplementation with CR ( $>30 \mathrm{~g} / \mathrm{d})$ will generally result in cell saturation, after which surplus CR will be removed from the body by renal filtration. While some claim this can lead to an increased load on both the liver and kidneys, empirical research is yet to find any such side effects in healthy individuals $[26,27]$. It is also worth noting that once supplementation has ceased, serum CR levels will return to their pre-supplementation level within a 30-day period [22].

\section{Methodology}

\section{Materials and Methods}

A range of databases, including PubMed, Google Scholar and EBSCO-host, were searched using terms concerning CR supplementation and athletic performance; including 'creatine', 'supplementation, 'high intensity training', 'ergogenic aid, 'performance', 'health', 'side effects', 'resistance', 'athlete', 'muscle strength', muscle power' and 'adaptations'. Studies evaluating the effects of CR supplementation on exercise performance in humans were selected for inclusion. Further references were found, appraised and included from the bibliographies of selected research articles.

\section{Result}

\section{General Ergogenic properties}

Once in the muscle, at rest, $\mathrm{CR}$ is phosphorylated by creatine-kinase (CK) to form phosphocreatine (PCr), an important substrate in the generation of muscle force production $[29,30]$. In the rest-to-exercise transition, the muscles begin to consume stores of adenosine triphosphate (ATP) by breaking the phosphoanhydride bonds. At this stage, the high energy yielding phosphoryl group of $\mathrm{PCr}$ is transferred to adenosine diphosphate (ADP) to resynthesize ATP (rephosphorylation), facilitating a greater intensity of work to be sustained [9]. This system acts as a temporal energy buffer, providing the majority of energy for the first 6-8s of muscular work. As PCr stores deplete, and ATP resynthesis diminishes, anaerobic glycolysis becomes the predominant energy source [28]. It has been theorized that the volume of $\mathrm{PCr}$ existent within the muscles will significantly influence the amount of energy generated during short periods of high intensity exercise [31,32], with early research by Katz et al. [33], stating that fatigue is more closely related to low PCr stores than high lactate content.

\section{Creatine and strength training}

A classic CR research study reported an increase in strength performance following 12 weeks of supplementation when combined with heavy resistance training ( $80 \%$ one repetition maximum) [34]. In this study, participants ingested $25 \mathrm{~g} /$ day CR for seven days (loading phase), followed by $5 \mathrm{~g} /$ day $\mathrm{CR}$ for the remainder of the study (maintenance phase). The participants significantly increased their muscular strength, fat free mass (FFM), muscular hypertrophy and total muscle CR concentrations over a control group. It was suggested that the significant effects recorded were accredited to an increased total CR pool, enabling a greater regeneration of ATP between exercise sets. Contemporary research has continued to explore $\mathrm{CR}$ administration and concurrent strength training, with numerous studies reporting similar significant ergogenic effects following supplementation protocols $[10,11,35,36]$.

Contradictory research by Bemben et al. [37] showed no additional benefits of supplementing CR when combined with a 14-week resistance training programme [37]. Participants ingested a placebo, 5 $\mathrm{g}$ of $\mathrm{CR}$ or $5 \mathrm{~g}$ of CR together with $35 \mathrm{~g}$ whey protein. While all trials showed improved muscular strength, there were no significant differences witnessed between groups. These conflicting results can partly be explained due to the lack of a pre-loading supplement protocol as recommended within CR research [38,39], and also due to supplementation occurring on training days only (three a week) as opposed to research based recommendations of throughout entire training protocol $[40,41]$.

\section{Creatine and intermittent/recurrent high intensity exercise}

Numerous researchers have focused on the effects CR supplementation has on intermittent, high intensity exercise, with many reporting improved performance varied supplementation protocols [42-45]. Early research conducted by Yquel et al. [46] evaluated the effects CR ingestion had on muscle power output and $\mathrm{PCr}$ resynthesis during recurrent bouts of maximal exercise. Participants performed eight bouts of maximal plantar flexion both pre and post CR ingestion interspaced with 30 s recovery. Both muscle power output and PCr resynthesis increased following completion of 
supplement protocol. Conclusions were drawn that the better conservation of muscle power output observed, following $\mathrm{CR}$ ingestion, was attributed to a greater resynthesis of PCr throughout the exercise protocol.

A further study examined the effects CR supplementation on blood lactate and time to exhaustion during incremental cycling exercise [12]. Subjects completed a maximal incremental test to exhaustion both before and after six days of CR supplementation. Lactate concentrations were significantly reduced during exercise following supplementation, with both time to exhaustion and maximal power output listed as approaching significant. It was concluded that the findings established that CR supplementation significantly reduces lactate concentrations during high intensity, intermittent exercise.

\section{Creatine and endurance exercise}

Although predominantly associated with short duration high intensity exercise, there is some evidence to support $\mathrm{CR}$ supplementation alongside long term aerobic activities. Early research conducted by Chwalbinska-Moneta [47] examined the effects $20 \mathrm{~g} / \mathrm{d}$ of $\mathrm{CR}$ had on the endurance performance of elite male rowers. Subjects were randomly assigned to either a placebo or supplement group, before completing an incremental exercise test on a rowing ergometer. Blood lactate and heart rate were taken throughout and time to exhaustion was logged. Both the mean individual lactate threshold and time to exhaustion rose significantly in the CR group when compared to the placebo group. The study concluded that the results gained indicted that CR supplementation increases lactate threshold and thus improves endurance in rowing.

Opposing research is more prominent in this area, with early research Thompson et al. [48] reporting six weeks of CR supplementation had no effect on aerobic endurance of female swimmers. A further meta-analysis conducted by Branch [18] highlighted that any endurance activities lasting longer than 150s rely on oxidative phosphorylation as a primary energy supply, and so once this mark is exceeded, the ergogenic potential of CR diminishes.

\section{Creatine and exercise: Summary of creatine and exercise performance}

Supplementation with $\mathrm{CR}$ has been shown to be an effective ergogenic aid across a range of sporting intensities. It is well established that CR supplementation has an ergogenic effect on both strength training and single and recurrent bouts of short duration high intensity exercise, with contemporary studies showing a positive effect from as little as seven days supplementation [44,49]. There are numerous mechanisms by which CR supplementation acts to augment athletic performance. During the CK reaction, CR is substrated resulting in the generation of $\mathrm{PCr}$. As previously mentioned, $\mathrm{PCr}$ is responsible for the re-phosphorylation of ADP to ATP during bursts of high intensity movements, and therefore greater quantities result in increased energy availability [50]. As PCr stores decline, phosphofructokinase production is stimulated, increasing the rate of glycolysis [51]. At this stage, $\mathrm{CR}$ has been shown to buffer the $\mathrm{pH}$ changes that occur during the accumulation of lactate and hydrogen ions, delaying the onset of acidosis and subsequent fatigue.

With regards to longer bouts of physical exertion, a lack of contemporary research exists. However, the majority of available research has shown $\mathrm{CR}$ to have little to no ergogenic benefits as exercise exceeds 150s [18]. This is due to a change in how energy is supplied (oxidative phosphorylation as opposed to PCr-CR system) to the requiring muscles.

\section{Safety and ethical considerations}

Since the late 1900's CR has continuously gained popularity as a supplement among the athletic population [52]. The use of this dietary intervention has been surrounded by both misconception and debate; with the media claiming that CR supplementation is both dangerous and unethical [31]. Many anecdotal claims concerning CR still in the include muscle cramping, dehydration, liver damage and gastrointestinal distress. While it is conceivable that athletes may experience these symptoms, contemporary research has shown that athletes are at no greater risk, and in fact, potentially a lesser risk of these symptoms, than those not supplementing with CR [53-55].

One of the more recurring claims associated with CR is that of increased renal distress through prolonged supplementation. Early research completed by Pritchard and Kalra [55] reported that CR supplementation had a deleterious effect on the renal function of a single participant following a 7 week supplementation programme. They recorded moderate decreases in renal function were recorded over time, and thus it was concluded this was strongly linked to the CR supplements that were being administered. However, future research highlighted concerns over the practices adopted during this study, stating that there was no scientific backing to the claims made due to the single participant already suffering from recurring renal failure [56]. A further report from Mesa et al. [1] concluded that due to the distorted information gathered and reported, the case report was very misleading. Table 2 summaries the current literature which has revealed that CR supplementation at several different dosages has had no adverse findings on renal kidney functioning.

\begin{tabular}{|c|c|c|c|c|}
\hline Authors & Sample & $\begin{array}{l}\text { Sample } \\
\text { characteristics }\end{array}$ & $\begin{array}{l}\text { Supplementation } \\
\text { protocol }\end{array}$ & $\begin{array}{l}\text { Renal } \\
\text { problems } \\
\text { recorded }\end{array}$ \\
\hline \multirow[t]{2}{*}{$\begin{array}{l}\text { Terjung et al. } \\
\text { [4] }\end{array}$} & 7 & Healthy females & $\begin{array}{l}20 \mathrm{~g} / \mathrm{d} \text { for } 5 \text { days }+ \\
3 \mathrm{~g} / \mathrm{d} \text { for } 8 \text { weeks }\end{array}$ & No \\
\hline & 7 & Healthy males & $20 \mathrm{~g} / \mathrm{d} /$ for 5 days & No \\
\hline $\begin{array}{l}\text { Gualano et al. } \\
\text { [27] }\end{array}$ & 18 & Trained males & $\begin{array}{l}10 \mathrm{~g} / \mathrm{d} \text { for } 12 \\
\text { weeks }\end{array}$ & No \\
\hline $\begin{array}{l}\text { Gualano et al. } \\
{[26]}\end{array}$ & 1 & $\begin{array}{l}\text { Healthy male } \\
\text { with one kidney }\end{array}$ & $\begin{array}{l}20 \mathrm{~g} / \mathrm{d} \text { for } 5 \text { days }+ \\
5 \mathrm{~g} / \mathrm{d} \text { for } 30 \text { days }\end{array}$ & No \\
\hline $\begin{array}{l}\text { Gualano et al. } \\
\text { [27] }\end{array}$ & 25 & $\begin{array}{l}\text { Males and } \\
\text { females with type } \\
2 \text { diabetes }\end{array}$ & $5 \mathrm{~g} / \mathrm{d}$ for 12 weeks & No \\
\hline $\begin{array}{l}\text { Neves JrM et } \\
\text { al. [27] }\end{array}$ & 13 & $\begin{array}{l}\text { Postmenopausal } \\
\text { women }\end{array}$ & $\begin{array}{l}20 \mathrm{~g} / \mathrm{d} \text { for } 1 \text { week }+ \\
5 \mathrm{~g} / \mathrm{d} \text { for } 11 \text { weeks }\end{array}$ & No \\
\hline $\begin{array}{l}\text { Terjung et al. } \\
{[4]}\end{array}$ & 48 & $\begin{array}{l}\text { Healthy males } \\
\text { and females }\end{array}$ & $\begin{array}{l}3 \mathrm{~g} / \mathrm{d} \text { for } 1 \text { week }+ \\
20 \mathrm{~g} / \mathrm{d} \text { for } 8 \text { weeks }\end{array}$ & No \\
\hline $\begin{array}{l}\text { Liddle et al } \\
{[30]}\end{array}$ & 26 & $\begin{array}{l}\text { Resistance } \\
\text { trained males }\end{array}$ & $\begin{array}{l}20 \mathrm{~g} / \mathrm{d} \text { for } 1 \text { week }+ \\
5 \mathrm{~g} / \mathrm{d} \text { for } 11 \text { weeks }\end{array}$ & No \\
\hline
\end{tabular}

Table 2: Research studies examining effects of creatine supplementation on renal function in adults. 
It would be difficult to consume the recommended dosages of $\mathrm{CR}$ via a balanced nutritious diet, and therefore supplementation is an obvious choice by athletes. In order for an athlete to gain enough CR to effectively equate to a loading strategy, it would require $3-4 \mathrm{~kg}$ of certain foods to be consumed for a period of 1-2 days. Despite being potentially unpalatable for most, a significant increase is lipids and proteins would but an unwanted addition. Furthermore, those with specific dietary requirements may struggle to consume CR rich foods due to restrictions i.e., vegetarians, vegans, religious diets. CR is not banned by any organization however the USA National Collegiate Athletic Association has a policy which restricts creatine provision to athletes from member teams [8]. With research showing that CR is safe to consume, even for prolonged periods (Table 2), it has been suggested that those advocating for restrictions are merely aware of the anecdotal misconceptions surrounding the supplement, and not the empirical based evidence. It has been Buford et al. [31] proposed that there is no difference between following a CR supplementation programme to increase $\mathrm{PCr}$ stores, and completing a carbohydrate loading programme to enhance glycogen stores [31]. It is worth noting that many researchers have argued that banning CR would in fact be unethical as it has been linked to reductions in musculoskeletal injuries [57], heat stress [58], and decreases in rehabilitation periods [59], as well as being a naturally occurring compound.

\section{Recommendations}

CR supplementation has been shown to positively impact upon performance across a range of sports, with the most prominent literature focusing on short-term, intermittent/recurrent, high intensity activities [45]. Specifically, there is strong evidence to suggest CR increased power output [43], repeated sprint ability [60], maximal strength [50] and FFM [11].

A typical CR supplement protocol reported comprises of by Mesa et al. [1] has a loading phase lasting 1-2 days $(4 \times 5 \mathrm{~g}$ CR over 5-7 $\mathrm{hr}$ intervals), followed by a maintenance phase for continuous supplementation thereafter (3-5 g CR per day). The majority of research surrounding $\mathrm{CR}$ and its ergogenic potential has used very similar protocols, with many reporting significant improvements across a range of variables. However, more recent research by Cooper et al. [13] found that a moderate protocol consisting of $1 \mathrm{~g}$ doses taken over ten hours ( $1 \mathrm{~g}$ every $30 \mathrm{~min}, 20 \mathrm{~g} \mathrm{CR}$ in total) for five days, resulted in reduced urinary $\mathrm{CR}$ when compared to a typical supplementation protocol. It was estimated that this decrease in urinary CR equated to an increase in TCr by $13 \%$, further increasing PCr stores and thus energy potential.

\section{Conclusion}

The use of CR as a dietary supplement is prevalent across amateur and professional athletes alike. With research showing a performance increase of $1 \%$ can be the difference between Olympic gold and not making the final, it is understood why athletes will turn to ergogenic aids to potentially gain an advantage [61]. Supplementation with CR has been advocated to improve both short-term and intermittent high intensity exercise, with some supporting literature for both mid and long-term bouts. Currently, no scientific evidence exists showing any unfavorable effects, even when supplementation is prolonged, providing correct protocols are followed and the participant is otherwise healthy.
It is recommended that those considering supplementation first establish a sound dietary foundation, ensuring a balance in the foods consumed as well as maintaining constant hydration [62]. Furthermore, supplementation will be insignificant in producing desired results without an appropriate training stimulus (e.g. a specific resistance based training programme). With regards to the supplementation protocol adopted, at this stage it is recommended that an athlete follow a traditional loading/maintenance programme as opposed to that recommended by contemporary research by Cooper et al. [13], as further examination research is needed to fully establish the benefits of novel and alternative protocols and whether alteration of the initial loading phase results in significantly greater outcomes.

\section{References}

1. Mesa JLM, Ruiz JR, Gonzalez-Gross MM, Sainz AG, Garzon MJC (2002) Oral creatine supplementation and skeletal muscle metabolism in physical exercise. Sports Med 32: 903-944.

2. Chanutin A (1926) The fate of creatine when administered to man. J Biol Chem 67: 29-41.

3. Mendel LB, Rose WC (1911) Experimental studies on creatine and creatinine. The role of the carbohydrates in creatine-creatinine metabolism. J Biol Chem 10: 213-253.

4. Terjung RL, Clarkson P, Eicher ER, Greenhaff PL, Hespel PJ, et al. (2000) American College of Sports Medicine Roundtable: The Physiological and Health Effects of Oral Creatine Supplementation. Med Sci Sports Exerc 32: 706-717.

5. Busko M (2004) Supplement muscles in the market. National Review of Medicine 1: 204-207.

6. Hall M, Trojian T (2013) Creatine supplementation. Current Sports Medicine Reports 12: 240-244.

7. Bemben MG, Lamont HS (2005) Creatine supplementation and exercise performance: Recent findings. Sports Medicine 35: 107-125.

8. Momaya A, Fawal M, Estes R (2015) Performance-enhancing substances in sports: A review of the literature. Sports Medicine 45: 517-531.

9. McKinnon NB, Graham MT, Tiidus PM (2012) Effect of creatine supplementation on muscle damage and repair following eccentricallyinduced damage to the elbow flexor muscles. J Sports Sci Med 11: 653-659.

10. Lanhers C, Pereira B, Naughton G, Trousselard M, Lesage FX, et al. (2015) Creatine supplementation and lower limb strength performance: A systematic review and meta-analyses. Sports Medicine 45: 1285-1294.

11. Antonio J, Ciccone V (2013) The effects of pre versus post workout supplementation of creatine monohydrate on body composition and strength. J Int Soc Sports Nutr 10.

12. Oliver JM, Joubert DP, Martin SE, Crouse SF (2013) Oral creatine supplementation's decrease of blood lactate during exhaustive, incremental cycling. Int J Sport Nutr Exerc Metab 23: 252-259.

13. Cooper R, Naclerio F, Allgrove J, Jimenez A (2012) Creatine supplementation with specific view to exercise/sports performance: an update. J Int Soc Sports Nutr 9: 33.

14. Bazzucchi I, Felici F, Sacchetti M (2009) Effect of short-term creatine supplementation on neuromuscular function. Med Sci Sports Exerc 41: 1934-1941.

15. Camic CL, Housh TJ, Zuniga JM, Traylor DA, Bergstrom HC, et al. (2014) The effects of polyethylene glycosylated creatine supplementation on anaerobic performance measures and body composition. J Strength Cond Res 28: 825-833.

16. Dobgenski V, Santos MG, Campbell B, Kreider R (2014) Short-term creatine supplementation suppresses the cortisol response to a highintensity swim-sprint workout. J Nutr Health Sci 1: 1-4.

17. Sculthorpe N, Grace F, Jones P, Fletcher I (2010) The effect of short-term creatine loading on active range of movement. Appl Physiol Nutr Metab 35: 507-511. 
18. Branch J (2003) Effect of creatine supplementation on body composition and performance: a meta-analysis. Int J Sport Nutr Exerc Metab 13: 198-226.

19. Bloch K, Schoenheimer R (1941) The Biological precursors of creatine. J Biol Chem 138: 167-194.

20. Nasrallah F, Feki M, Kaabachi N (2010) Creatine and creatine deficiency syndromes: biochemical and clinical aspects. Pediatr Neurol 42: 163-171.

21. Walker J (2009) Creatine: biosynthesis, regulation and function. In: Meister A (ed.) Advances in enzymology and related areas of molecular biology. New York: John Wiley and Sons, pp: 177-242.

22. Smith RN, Agharkar AS, Gonzales EB (2014) A review of creatine supplementation in age-related diseases: more than a supplement for athletes. F1000Res 3: 222.

23. Brosnan JT, da Silva RP, Brosnan ME (2011) The metabolic burden of creatine synthesis. Amino acids 40: 1325-1331.

24. Barr SI, Rideout CA (2004) Nutritional considerations for vegetarian athletes. Nutrition 20: 696-703.

25. Burke DG, Candow DG, Chilibeck PD, MacNeil LG, Roy BD, et al. (2008) Effect of creatine supplementation and resistance-exercise training on muscle insulin-like growth factor in young adults. Int J Sport Nutr 18: 389-398.

26. Gualano B, Artioli GG, Poortmans JR, Junior AHL (2010) Exploring the therapeutic role of creatine supplementation. Amino acids 38: 31-44.

27. Neves Jr M, Gualano B, Roschel H, Lima FR, Lúcia de Sá-Pinto A, et al. (2011) Effect of creatine supplementation on measured glomerular filtration rate in postmenopausal women. Appl Physiol Nutr Metab 36: 419-422.

28. Tarnopolsky MA (2010) Caffeine and creatine use in sport. Ann Nutr Metab 57: 1-8.

29. Greenhaff PL, Casey A, Short AH, Harris R, Soderlund K, et al. (1993) Influence of oral creatine supplementation of muscle torque during repeated bouts of maximal voluntary exercise in man. Clinical Science 84: 565-571.

30. Liddle DG, Connor DJ (2013) Nutritional supplements and ergogenic AIDS. Primary Care: Clinics in Office Practice 40: 487-505.

31. Buford T, Kreider R, Stout J, Greenwood M, Campbell B, et al. (2007) International Society of Sports Nutrition position stand: Creatine supplementation and exercise. Int Soc Sports Nutr4: 1550-1783.

32. Plowman SA, Smith DL (2013) Exercise physiology for health fitness and performance. Wolters Kluwer: Lippincott Williams \& Wilkins, Netherlands.

33. Katz A, Sahlin K, Henriksson J (1986) Muscle ATP turnover rate during isometric contraction in humans. J Appl Physiol 60: 1839-1842.

34. Volek JS, Duncan ND, Mazzetti SA, Staron RS, Putukian M, et al. (1999) Performance and muscle fibre adaptations to creatine supplementation and heavy resistance training. Med Sci Sports Exerc 31: 1147-1156.

35. Candow DG, Chilibeck PD, Burke DG, Mueller KD, Lewis JD (2011) Effect of different frequencies of creatine supplementation on muscle size and strength in young adults. J Strength Cond Res 25: 1831-1838.

36. Souza-Junior TP, Willardson JM, Bloomer R, Leite RD, Fleck SJ, et al. (2011) Strength and hypertrophy responses to constant and decreasing rest intervals in trained men using creatine supplementation. J Int Soc Sports Nutr 8: 17 .

37. Bemben MG, Witten MS, Carter JM, Eliot KA, Knehans AW, et al. (2010) The effects of supplementation with creatine and protein on muscle strength following a traditional resistance training program in middleaged and older men. J Nutr Health Aging 14: 155-159.

38. Van Loon LJC, Oosterlaar AM, Hartgens F, Hesselink MKC, Snow RJ (2003) Effects of creatine loading and prolonged creatine supplementation on body composition, fuel selection, sprint and endurance performance in humans. Clinical Science 104: 153-162.

39. Zuniga J, Housh T, Camic C, Hendrix C, Mielke M, et al. (2012) The effects of creatine monohydrate loading on anaerobic performance and one-repetition maximum strength. J Strength Cond Res 26: 1651-1656.
40. Devries MC, Phillips SM (2014) Creatine supplementation during resistance training in older adults-a meta-analysis. Med Sci Sports Exerc 46: 1194 - 1203.

41. Rahimi R (2011) Creatine supplementation decreases oxidative DNA damage and lipid peroxidation induced by a single bout of resistance exercise. J Strength Cond Res 25: 3448-3455.

42. Barber JJ, McDermott AY, McGaughey KJ, Olmstead JD, Hagobian TA (2013) Effects of combined creatine and sodium bicarbonate supplementation on repeated sprint performance in trained men. J Strength Cond Res 27: 252-258.

43. Claudino JG, Mezencio B, Amaral S, Zanetti V, Benatti F, et al. (2014) Creatine monohydrate supplementation on lower-limb muscle power in Brazilian elite soccer players. J Int Soc Sports Nutr 11: 32.

44. Deminice R, Rosa FT, Franco GS, Jordao AA, de Freitas EC (2013) Effects of creatine supplementation on oxidative stress and inflammatory markers after repeated-sprint exercise in humans. Nutrition 29: 1127-1132.

45. Salles-Painelli V, Alves VT, Ugrinowitsch C, Benatti FB, Artioli GG, et al. (2014) Creatine supplementation prevents acute strength loss induced by concurrent exercise. Eur J Appl Physiol 114: 1749-1755.

46. Yquel RJ, Arsac LM, Thiaudiere E, Canioni P, Manier G (2002) Effect of creatine supplementation on phosphocreatine resynthesis, inorganic phosphate accumulation and $\mathrm{pH}$ during intermittent maximal exercise. J Sports Sci 20: 427-438.

47. Chwalbinska-Moneta J (2003) Effect of creatine supplementation on aerobic performance and anaerobic capacity in elite rowers in the course of endurance training. Int J Sport Nutr Exerc Metab 13: 173-183.

48. Thompson CH, Kemp GJ, Sanderson AL, Dixon RM, Styles P, et al. (1996) Effect of creatine on aerobic and anaerobic metabolism in skeletal muscle in swimmers. Br J Sports Med 30: 222-225.

49. Mirzaei B, Rahmani-Nia F, Salehi Z, Rahimi R (2013) Effects of creatine monohydrate supplementation on oxidative DNA damage and lipid peroxidation induced by acute incremental exercise to exhaustion in wrestlers. Kinesiology 45: 30-40.

50. Karimian J, Esfahani PS (2011) Supplement consumption in body builder athletes. J Res Med Sci 16: 1347-1354.

51. Volek J, Kraemer W (1996) Creatine supplementation: Its effect on human muscular performance and body composition. J Strength Cond Res 10: 200-210.

52. Dalbo VJ, Roberts MD, Stout JR, Kerksick CM (2008) Putting to rest the myth of creatine supplementation leading to muscle cramps and dehydration. Br J Sports Med 42: 567-573.

53. Cook C, Crewther B, Kilduff L, Drawer S, Gaviglio C (2011) Skill execution and sleep deprivation: Effects of acute caffeine or creatine supplementation - a randomized placebo-controlled trial. J Int Soc Sports Nutr 8: 1-8.

54. Kim HJ, Kim CK, Carpentier A, Poortmans JR (2011) Studies on the safety of creatine supplementation. Amino Acids 40: 1409-1418.

55. Sobolewski E, Thompson B, Smith A, Ryan E (2011) The physiological effects of creatine supplementation on hydration: A review. Am J Lifestyle Med 5: 320-327.

56. Pritchard NR, Kalra PA (1998) Renal dysfunction accompanying oral creatine supplements. Lancet 351: 1252-1253.

57. Poortmans JR, Francaux M (2000) Adverse effects of creatine supplementation fact or fiction?. Sports Med 30: 155-170.

58. Tyler TF, Nicholas SJ, Hershman EB, Glace BW, Mullaney MJ, et al. (2004) The effect of creatine supplementation on strength recovery after anterior cruciate ligament (ACL) reconstruction: A randomized, placebocontrolled, double-blind trial. Am J Sports Med 32: 383-391.

59. Kilduff L, Georgiades E, James N, Minnion R, Mitchell M, et al. (2004) The effects of creatine supplementation on cardiovascular, metabolic, and thermoregulatory responses during exercise in the heat in endurancetrained humans. Int J Sport Nutr Exerc Metab 14: 443-502. 
Citation: Dorrell HF, Gee TI, Middleton G (2016) An Update on Effects of Creatine Supplementation on Performance: A Review. Sports Nutr Ther 1: 107. doi:10.4172/snt.1000107

Page 6 of 6

60. Kley RA, Tarnopolsky MA, Vorgerd M (2008) Creatine treatment in muscle disorders: A meta-analysis of randomised controlled trials. J Neurol Neurosurg Psychiatry 79: 366-367.

61. Mohebbi H, Rahnama N, Moghadassi M, Ranjbar K (2012) Effect of creatine-supplementation on sprint and skill performance in young soccer players. Middle East J Sci Res 12: 397-401.
62. Buell JL, Franks R, Ransone J, Powers ME, Laquale KM, et al. (2013) National Athletic Trainers' Association position statement: Evaluation of dietary supplements for performance nutrition. J Athl Train 48: 124-136. 